\title{
Coag-Flocculation Studies of Afzelia Bella Coagulant (ABC) in Coal Effluent Using Single and Simulated Multi Angle Nephelometry
}

\author{
M.C. Menkiti* and O.D. Onukwuli \\ Department of Chemical Engineering, Nnamdi Azikiwe University, Awka, Nigeria. \\ *Corresponding author: cmenkiti@yahoo.com \\ Telephone: +2348037441882
}

\begin{abstract}
Following the need for the use of environmentally friendly, renewable resource in industrial processes, this work explores the potential of an effective application in pilot scale of Afzelia bella seed as a coag-flocculant. The study evaluates the coag-flocculation efficiency and functional kinetic parameter response to varying $\mathrm{pH}$ and dosage of coal washery effluent and $A B C$ respectively. The maximum coag-flocculation performance is recorded at rate constant, $K$ of $3.3333 \times 10^{-3} \mathrm{~m}^{3} / \mathrm{kg} . \mathrm{s}$, dosage of $\left(0.3\right.$ and $\left.0.2 \mathrm{~kg} / \mathrm{m}^{3}\right) ; \mathrm{pH}$ of 2 and coagulation period, $\tau_{1 / 2}$ of $28.1216 \mathrm{~s}$ while the minimum is recorded at $K$ of $1.6667 \times 10^{-4} \mathrm{~m}^{3} / \mathrm{kg}$.s, dosage of $0.2 \mathrm{~kg} / \mathrm{m}^{3}$, pH of 10 and $\tau_{1 / 2}$ of $562.365 \mathrm{~s}$. The least value of coag-flocculation efficiency, $E(\%)>89.00$. Simulated and unsimulated values of rate constants $K_{s}$ and $K$ respectively are in close agreement, validating the concept of perikinetics. The potential of $A B C$ as an effective organic coag-flocculant has been established. The results confirm that theory of rapid coagflocculation holds for the aggregation of coal washery effluent using $A B C$ and at the conditions of the experiment.
\end{abstract}

Keywords: Afzelia bella; coag-flocculation; coal effluent; kinetics; nephelometry.

\section{INTRODUCTION}

\subsection{Background}

In waste water treatment operations, the process of coag-flocculation (coagulation / flocculation) is employed to separate suspended solids from waste effluent; via floc formation $[1,2,3,4$,$] . Among the factors that can affect the formation of the flocs are temperature, \mathrm{pH}$, effluent quality e.t.c. [5]. 
Coag-flocculation can be achieved by the use of inorganic substances (alum, $\mathrm{FeCl}_{3}$ e.t.c) and natural organic derivatives. However, the caog-flocculation behaviors of these inorganic aggregates agents are well documented with little or no attention given to the study of the animal and plant material as a potential source of organic derived coagulant. To this end, focus is hereby given to the study of a plant material, Afzelia bella bean, as a potential source of coagulant derivative. Afzelia bella is a leguminous plant, rich in protein, fat and starch. It is a native to tropical climate such as Eastern Nigeria [6].

Afzelia bella is an edible, non-toxic and biodegradable substance. Previous results obtained in its thickening properties highlight promise of renewable material with extensive application in water treatment technology.

However, in spite of the abundance of Afzelia bella in our local communities in Nigeria, little or no comprehensive work has been reported on its coag-flocculating application. Against this backdrop, this work endeavors to explore and generate interest in the utilization of Afzelia bella as a coagulant. In line with this, the work focuses on coag-flocculation performance and kinetics of $\mathrm{ABC}$ under varying $\mathrm{pH}$ of coal washery effluent (a typical medium for this kind of study) using single and simulated multi angle light scattering techniques. Thus if well harnessed and developed, $\mathrm{ABC}$ can be an alternative to or be used in conjunction with the inorganic coagulant. Ultimately, post usage handling and health challenges posed by the inorganic coagulant can be reduced.

\subsection{Theoretical Principles and Model Development}

For a uniformly coag-flocculating equilibrium phase with negligible influence of external forces [7]:

$$
\mu_{i}=\bar{G}_{i}=\left[\frac{\partial G}{\partial n_{i}}\right]_{P, T, n}=\mathrm{a} \text { constant }
$$

And

$$
-f_{d}=\frac{K_{B} T}{C_{i}} \frac{d C_{i}}{d x}
$$

Where $G$ is the total Gibbs free energy

$n_{i}$ is the number of moles of component $i$

$\mu_{i}$ is chemical potential

$C_{i}$ is concentration

$x$ is diffusion distance

$f_{d}$ is viscous drag force.

$K_{B}$ is Boltzmann's constant $(\mathrm{J} / \mathrm{K})$

$T$ is Absolute temperature $(\mathrm{K})$

But from Ficks law 
$D^{\prime}=\frac{-f_{d}}{B} \frac{C_{i}}{\left(d C_{i} / d x\right)}$

Where $D^{\prime}$ is diffusion coefficient

$B$ is friction factor

Comparing equation 2 and 3 generates Einstein's equation:

$D^{\prime}=\frac{K_{B} T}{B}$

For similar phase, the rate of successful collision between particles sizes $\mathrm{i}$ and $\mathrm{j}$ (mass concentration/time) to form particle of size $k$ is $[8,5]$ :

$\mathrm{N}_{\mathrm{ij}}=\varepsilon_{\mathrm{p}} \beta(\mathrm{i}, \mathrm{j}) \mathrm{n}_{\mathrm{i}} \mathrm{n}_{\mathrm{j}}$

where

$\varepsilon_{\mathrm{p}}=$ collision efficiency

$\beta(\mathrm{i}, \mathrm{j})=$ collision factor between particles of size $\mathrm{i}$ and $\mathrm{j}$

$\mathrm{n}_{\mathrm{i}} \mathrm{n}_{\mathrm{j}}=$ particle concentration for particles of size $\mathrm{i}$ and $\mathrm{j}$, respectively.

Assuming monodisperse, no break up and bi particle collision, the general model for perikinetic coag-flocculation is given as $[9,5]$ :

$\frac{d n_{k}}{d t}=\frac{1}{2} \sum_{i+j=k} \beta(i, j) n_{i} n_{j}-\sum_{i=1}^{\infty} \beta(i, k) n_{i} n_{k}$

where $\frac{d n_{k}}{d t} \quad$ is the rate of change of concentration of particle of size $k$ (concentration / time).

$\beta$ is a function of the coag-flocculation transport mechanism.

The appropriate value of $\beta$ for Brownian transport is given by [10]:

$\beta_{B R}=\frac{8}{3} \varepsilon_{p} \frac{K_{B} T}{\eta}$

The generic aggregation rate of particles (during coagulation / flocculation) can be derived by the combination of equations 6 and 7 to yield:

$-\frac{d N_{t}}{d t}=K N_{t}^{\alpha}$

Where $N_{t}$ is total particle concentration at time $t, N_{t}=\sum n_{k}$ (mass / volume)

$K$ is the Menkonu coag-flocculation rate constant for $\alpha^{\text {th }}$ order.

$\alpha$ is the order of coag-flocculation process .

Meanwhile $K=\frac{1}{2} \beta_{B R}$

Also, $\beta_{B R}=2 \varepsilon_{p} K_{R}$

Combining equations 8,9 and 10 produce:

$-\frac{d N_{t}}{d t}=\varepsilon_{p} K_{R} N_{t}^{\alpha}$

Where $K_{R}$ is the Von smoluchowski rate constant for rapid coagulation [11]. 
However $K_{R}=8 \pi a D^{\prime}$

$$
R_{p}=2 a
$$

Where $a$ is particle radius.

From Einstein's equation: $D^{\prime}=K_{B} T / B$

From Stoke's equation $: B=6 \pi \eta a$

where $\eta$ is the viscosity of the coag-flocculating fluid

Combining equations 11 to14 gives:

$$
-\frac{d N_{t}}{d t}=\frac{4}{3} \varepsilon_{p} \frac{K_{B} T}{\eta} N_{t}^{\alpha}
$$

Comparing equations 8 and 15 show:

$$
K=\frac{4}{3} \varepsilon_{p} \frac{K_{B} T}{\eta}
$$

For perikinetic aggregation, $\alpha$ theoretically equals 2 as would be shown below $[12,7]$ :

From Fick's law,

$$
J_{f}=D^{\prime} 4 \pi R_{p}^{2} \frac{d N_{t}}{d R}
$$

Integrating equation 17 at initial conditions $N_{t}=0, R=2 a$ :

$$
\frac{J_{f}}{D^{\prime} 4 \pi} \int_{0}^{R_{p}} \frac{d R_{p}}{R_{p}{ }^{2}}=\int_{N_{0}}^{N_{t}} d N_{t}
$$

Thus $J_{f}=8 \pi D^{\prime} a N_{0}$

For central particle of same size undergoing Brownian motion, the initial rate of rapid coag-flocculation is:

$$
\begin{aligned}
& -\frac{d N_{t}}{d t}=J_{f} \cdot \varepsilon_{p} \cdot N_{0} \\
& =\frac{4}{3} \varepsilon_{p} \frac{K_{B} T}{\eta} \cdot N_{0}^{2} \\
& \equiv \frac{4}{3} \varepsilon_{p} \frac{K_{B} T}{\eta} N_{t}^{2} \text { at } t>0
\end{aligned}
$$

Hence, from equation $21, \alpha=2$

For $\alpha=2$; equivalence of equation 8 yields:

$$
\frac{d N}{d t}=-K N^{2}
$$

Hence:

$\int_{N_{0}}^{N} \frac{d N}{N^{2}}=-K \int_{0}^{t} d t$

Thus $\frac{1}{N}=K t+1 / N_{0}$

Plot of $(1 / N)$ Vs $t$ produces a slope of $K$ and intercept of $1 / N_{0}$. 
For the evaluation of coagulation period $\left(\tau_{1 / 2}\right)$, from Equation 23:

$$
N=\frac{N_{0}}{\left[1+\frac{t}{\left(1 / N_{0} K\right)}\right]}
$$

Where $\tau=\left[1 / N_{0} K\right]$

Hence:

$$
N=\frac{N_{0}}{1+(t / \tau)}
$$

When $t=\tau$, equation 26 becomes

$$
N=N_{0} / 2
$$

Therefore as $N_{0} \rightarrow 0.5 N_{0} ; \tau \rightarrow \tau_{1 / 2}$

Hence $\tau_{1 / 2}=1 /\left(0.5 N_{0} K\right)$

For Brownian (perikinetic) aggregation at early stages ( $t \leq 30$ minutes), equation 6 can be solved exactly, resulting in the generic expression

$$
\frac{N_{m(t)}}{N_{0}}=\frac{\left[t / \tau^{\prime}\right]^{m-1}}{\left[1+t / \tau^{\prime}\right]^{m+1}}
$$

Where $\tau^{\prime}=2 \tau$

Hence, for singlets $(m=1)$

$$
N_{1}=N_{0}\left[\frac{1}{\left(1+t / \tau^{\prime}\right)^{2}}\right]
$$

For doublets $(m=2)$

$$
N_{2}=N_{0}\left[\frac{\left(t / \tau^{\prime}\right)}{\left(1+t / \tau^{\prime}\right)^{3}}\right]
$$

For triplets $(m=3)$

$$
N_{3}=N_{0}\left[\frac{\left(t / \tau^{\prime}\right)^{2}}{\left(1+t / \tau^{\prime}\right)^{4}}\right]
$$

Also for the coagulating phase, the intensity of light scattered from suspension of monodispersed phase is described as [11]:

$I\left(q, \mathrm{~T}_{d}\right)=I(q, 0)\left\lfloor 1+2 \sum_{m=2}^{\infty} C_{m}\left(\mathrm{~T}_{d}\right) A_{m}(q)\right\rfloor$

Where $\mathrm{I}\left(\mathrm{q}, T_{d}\right)$ is the intensity of light scattered by the initially unaggregated suspension ; $\mathrm{T}_{d}=\mathrm{t} / \tau^{\prime}$ (dimensionless time) 
$q$ is the scattering wave vector

$q=\left(\frac{4 \pi}{\lambda_{0}}\right) n_{0} \sin (0.5 \theta)$

where $\lambda_{0}$ is the wave length of the laser incident light in Vacuum, $\left(\lambda_{0}=2 \pi a / 6\right)$

$n_{0}$ is the refractive index of the suspending medium

$\theta$ is the scattering angle

$\mathrm{A}_{\mathrm{m}}$ is the form factor for an aggregate consisting of $\mathrm{m}$ primary particles.

$a$ is radius of particles sphere.

If the coagulating medium obeys the Rayleigh-Gans-Debye (RGD) approximations, then

$$
A_{m}(q)=\sum_{i}^{m} \sum_{j>1}^{m} \frac{\sin q r_{i}}{q r_{i j}}
$$

Where $\mathrm{r}_{\mathrm{ij}}$ is the centre-to-centre separation of primary particles $i$ and $j$ in the given $\mathrm{m}$-fold aggregate. The summation accounts for all pairs of particle centers in the aggregate.

The expression for the scattered intensity in view of many possible configurations arising from larger aggregates is:

$$
I\left(q, \mathrm{~T}_{d}\right)=I(q, 0)\left[1+2 \frac{\sin q d_{0}}{q d_{0}} \frac{\mathrm{T}_{d}}{\left(1+\mathrm{T}_{d}\right)^{3}}+2 \sum_{m=3}^{\infty} C_{m}\left(\mathrm{~T}_{d}\right) A_{m}(q)\right]
$$

The form factors are given by an average of all contributing structures where $d_{0}$ is hard core interaction diameter of singlets.Differentiating equation 36 as $t \rightarrow 0$, yields:

$$
\begin{aligned}
& \frac{I}{I(q, 0)}\left(\frac{d I(q, t)}{d t}\right)_{t \rightarrow 0}=\frac{d}{d t}\left[1+2 \frac{\sin q d_{0}}{q d_{0}} \frac{\mathrm{T}_{d}}{\left(1+\mathrm{T}_{d}\right)^{3}}+2 \sum_{m=3}^{\infty} C_{m}\left(\mathrm{~T}_{d}\right) A_{m}(q)\right] \\
& \frac{I}{I(q, 0)}\left(\frac{d I(q, t)}{d t}\right)_{t \rightarrow 0}=\left[\beta_{B R} N_{0} \frac{\sin q d_{0}}{q d_{0}}\right]
\end{aligned}
$$

Using simulated version of equation $38, K_{S}$ (simulated $K$ ) can easily be determined at several scattering angles. A plot of $\frac{I}{I(q, 0)}\left(\frac{d I(q, t)}{d t}\right)_{t \rightarrow 0} V S \frac{\sin q d_{0}}{q d_{0}}$ gives a slope of $N_{0} \beta_{B R}$ from where $\left(K_{S}\right)_{t \rightarrow 0}$ could be determined.

\section{MATERIALS AND METHODS.}

The sample of Afzelia bella was sourced from Nsugbe,Anambra State, Nigeria and processed to $\mathrm{ABC}$ based on the work reported by Adebowale and Adebowale [13].

The jar test was conducted based on standard Bench scale Nephelometric method (single angle procedure) for the examination of water and waste water [14, 15] using model WZS185 MC Turbidimeter, APPNo 688644A Gulenhamp magnetic stirrer and mettler Toledo Delta $320 \mathrm{pH}$ meter.

For the simulation, excel package was used while $d_{0}=1 \mu \mathrm{m}[16,7]$ and $n_{0}$ [17] were generated from literature and simple experiment respectively. 


\section{RESULTS AND DISCUSSION}

\subsection{Coag-flocculation Parameters}

The values of caog-flocculation reaction parameters are presented in Tables 1 to 6. For all cases of dosages and $\mathrm{pH}$, the value of $\alpha$ is 2 , though with the exception of few, the corresponding value of $R^{2}$ is generally $>0.9$. This result actually emphasizes its consistency with Von Smoluchowski theory of coagulation. Meanwhile, it should be noted that $\alpha$ relates with $K$ inversely. Since $K$ is rate per concentration and $K$ is associated with energy barrier $(K T)$, it is understandable that for higher $\alpha$ to be obtained, lower $K$ is a necessary condition for such phenomenon [12]. $K\left(=0.5 \beta_{B R}\right)$ values appreciably are less sensitive to a given $\mathrm{pH}$ as the dosage of $\mathrm{ABC}$ changes from $0.1 \mathrm{~kg} / \mathrm{m}^{3}$ to $0.5 \mathrm{~kg} / \mathrm{m}^{3}$.This may be as a result of situation where same or similar coag-flocculation mechanism is controlling the process. Also, the variation in $K_{R}$ is generally minimal; following insignificant changes in values of temperature and viscosity of the coag-flocculation medium.

At nearly invariant values of $K_{R}, \varepsilon_{P}$ relates directly to $2 K=\beta_{B R}$. The consequence is that high $\varepsilon_{P}$ results in high kinetic energy to overcome the zeta potential. The implication is that the double layer is either reduced or the colloids destabilized to actualize low $\tau_{1 / 2}$ in favor of high rate of coagulation. The results show that high values of $\tau_{1 / 2}$ corresponds to low $\varepsilon_{P}$ and $K$, and indication of repulsion in the system. $\tau_{1 / 2}$ values lie within the range of previous works where milliseconds had been reported [7].

Table1: Coag-flocculation Functional parameters for varying pH and constant dosage of $0.1 \mathrm{~kg} / \mathrm{m}^{3} \mathrm{ABC}$

\begin{tabular}{llllll}
\hline Parameter & $\mathbf{p H = 2}$ & $\mathbf{p H = 4}$ & $\mathbf{p H = 6}$ & $\mathbf{p H = 8}$ & $\mathbf{p H = 1 0}$ \\
\hline$\alpha$ & 2 & 2 & 2 & 2 & 2 \\
$R^{2}$ & 0.976 & 0.907 & 0.989 & 0.944 & 0.937 \\
$K\left(\mathrm{~m}^{3} / \mathrm{kg} . \mathrm{s}\right)$ & $1.667 \times 10^{-3}$ & $3.333 \times 10^{-4}$ & $1 \times 10^{-3}$ & $3.333 \times 10^{-4}$ & $1.667 \times 10^{-4}$ \\
$\beta_{B r}\left(\mathrm{~m}^{3} / \mathrm{kg} . \mathrm{s}\right)$ & $3.333 \times 10^{-3}$ & $6.667 \times 10^{-4}$ & $2 \times 10^{-3}$ & $6.667 \times 10^{-4}$ & $3.333 \times 10^{-4}$ \\
$K_{R}\left(\mathrm{~m}^{3} / \mathrm{s}\right)$ & $1.273 \times 10^{-17}$ & $1.470 \times 10^{-17}$ & $1.274 \times 10^{-16}$ & $1.470 \times 10^{-16}$ & $1.470 \times 10^{-16}$ \\
$\varepsilon_{p}\left(\mathrm{~kg}^{-1}\right)$ & $2.618 \times 10^{14}$ & $4.535 \times 10^{12}$ & $1.570 \times 10^{13}$ & $4.535 \times 10^{12}$ & $2.268 \times 10^{12}$ \\
$\tau_{1 / 2}(s)$ & 56.237 & 281.19 & 93.748 & 281.191 & 562.365 \\
$(S P)_{0}^{c}\left(\mathrm{~kg} / \mathrm{m}^{3}\right)$ & 0.417 & 1.25 & 0.526 & 1 & 1.667 \\
$\left(N_{p}\right)_{0}^{c}\left(\mathrm{~m}^{3}\right)$ & $2.5 \times 10^{26}$ & $7.5 \times 10^{26}$ & $3.1694 \times 10^{26}$ & $6.0221 \times 10^{26}$ & $10.0371 \times 10^{26}$ \\
$-r\left(\mathrm{~kg} / \mathrm{m}^{3} . s\right)$ & $1.667 \times 10^{-3} \mathrm{c}^{2}$ & $3.333 \times 10^{-3} \mathrm{c}^{2}$ & $1 \times 10^{-3} \mathrm{c}^{2}$ & $3.333 \times 10^{-4} \mathrm{c}$ & $1.667 \times 10^{-4} \mathrm{c}$ \\
\hline
\end{tabular}


Table2: Coag-flocculation Functional parameters for varying $\mathrm{pH}$ and constant dosage of $0.2 \mathrm{~kg} / \mathrm{m}^{3}$ ABC

\begin{tabular}{llllll}
\hline Parameter & $\mathbf{p H = 2}$ & $\mathbf{p H = 4}$ & $\mathbf{p H = 6}$ & $\mathbf{p H = 8}$ & $\mathbf{p H = 1 0}$ \\
\hline$\alpha$ & 2 & 2 & 2 & 2 & 2 \\
$R^{2}$ & 0.977 & 0.866 & 0.991 & 0.982 & 0.893 \\
$K\left(\mathrm{~m}^{3} / \mathrm{kg} . \mathrm{s}\right)$ & $3.333 \times 10^{-3}$ & $3.333 \times 10^{-4}$ & $1.167 \times 10^{-3}$ & $3.333 \times 10^{-4}$ & $1.667 \times 10^{-4}$ \\
$\beta_{B r}\left(\mathrm{~m}^{3} / \mathrm{kg} . \mathrm{s}\right)$ & $6.667 \times 10^{-3}$ & $6.667 \times 10^{-4}$ & $3.333 \times 10^{-3}$ & $6.667 \times 10^{-4}$ & $3.333 \times 10^{-4}$ \\
$K_{R}\left(\mathrm{~m}^{3} / \mathrm{s}\right)$ & $1.639 \times 10^{-17}$ & $1.6250 \times 10^{-16}$ & $1.639 \times 10^{-16}$ & $1.625 \times 10^{-16}$ & $1.625 \times 10^{-16}$ \\
$\varepsilon_{p}\left(\mathrm{~kg}^{-1}\right)$ & $4.072 \times 10^{14}$ & $4.102 \times 10^{12}$ & $2.034 \times 10^{13}$ & $4.102 \times 10^{12}$ & $2.051 \times 10^{12}$ \\
$\tau_{1 / 2}(s)$ & 28.122 & 281.191 & 80.337 & 281.19 & 562.366 \\
$(S P)_{0}^{c}\left(\mathrm{~kg} / \mathrm{m}^{3}\right)$ & 0.526 & 1.25 & 0.526 & 1 & 1.667 \\
$\left(N_{p}\right)_{0}^{c}\left(\mathrm{~m}^{3}\right)$ & $3.167 \times 10^{26}$ & $7.528 \times 10^{26}$ & $3.346 \times 10^{26}$ & $0.675 \mathrm{E}-4$ & $0.675 \mathrm{E}-4$ \\
$-r\left(\mathrm{~kg} / \mathrm{m}^{3} . s\right)$ & $3.333 \times 10^{-3} \mathrm{c}^{2}$ & $3.333 \times 10^{-4} \mathrm{c}^{2}$ & $1.167 \times 10^{-3} \mathrm{c}^{2}$ & $3.333 \times 10^{-4} \mathrm{c}^{2}$ & $1.667 \times 10^{-4} \mathrm{c}^{2}$ \\
\hline
\end{tabular}

Table3: Coag-flocculation Functional parameters for varying $\mathrm{pH}$ and constant dosage of $0.3 \mathrm{~kg} / \mathrm{m}^{3}$ ABC

\begin{tabular}{llllll}
\hline Parameter & $\mathbf{p H = 2}$ & $\mathbf{p H = 4}$ & $\mathbf{p H = 6}$ & $\mathbf{p H = 8}$ & $\mathbf{p H = 1 0}$ \\
\hline$\alpha$ & 2 & 2 & 2 & 2 & 2 \\
$R^{2}$ & 0.983 & 0.620 & 0.968 & 0.996 & 0.9347 \\
$K\left(\mathrm{~m}^{3} / \mathrm{kg} . \mathrm{s}\right)$ & $3.333 \times 10^{-3}$ & $3.333 \times 10^{-4}$ & $1.167 \times 10^{-3}$ & $1.500 \times 10^{-3}$ & $1.667 \times 10^{-4}$ \\
$\beta_{B r}\left(\mathrm{~m}^{3} / \mathrm{kg} . \mathrm{s}\right)$ & $6.667 \times 10^{-3}$ & $6.667 \times 10^{-4}$ & $3.333 \times 10^{-3}$ & $3 \times 10^{-3}$ & $3.333 \times 10^{-4}$ \\
$K_{R}\left(\mathrm{~m}^{3} / \mathrm{s}\right)$ & $1.303 \times 10^{-16}$ & $1.315 \times 10^{-16}$ & $1.307 \times 10^{-16}$ & $1.333 \times 10^{-16}$ & $1.242 \times 10^{-16}$ \\
$\varepsilon_{p}\left(\mathrm{~kg}^{-1}\right)$ & $5.117 \times 10^{13}$ & $5.069 \times 10^{12}$ & $2.551 \times 10^{13}$ & $2.251 \times 10^{13}$ & $2.684 \times 10^{12}$ \\
$\tau_{1 / 2}(s)$ & 28.122 & 281.191 & 80.337 & 62.486 & 562.365 \\
$(S P)_{0}^{c}\left(\mathrm{~kg} / \mathrm{m}^{3}\right)$ & 0.434 & 1.429 & 0.526 & 0.526 & 1.667 \\
$\left(N_{p}\right)_{0}^{c}\left(\mathrm{~m}^{-3}\right)$ & $2.614 \times 10^{26}$ & $8.603 \times 10^{26}$ & $3.168 \times 10^{26}$ & $3.168 \times 10^{26}$ & $10.037 \times 10^{26}$ \\
$-r\left(\mathrm{~kg} / \mathrm{m}^{3} . s\right)$ & $3.333 \times 10^{-3} \mathrm{c}^{2}$ & $3.333 \times 10^{-4} \mathrm{c}^{2}$ & $1.167 \times 10^{-3} \mathrm{c}^{2}$ & $3.333 \times 10^{-4} \mathrm{c}^{2}$ & $1.667 \times 10^{-4} \mathrm{c}^{2}$ \\
\hline
\end{tabular}


Table 4: Coag-flocculation Functional parameters for varying $\mathrm{pH}$ and constant dosage of $0.4 \mathrm{~kg} / \mathrm{m}^{3} \mathrm{ABC}$

\begin{tabular}{llllll}
\hline Parameter & $\mathbf{p H = 2}$ & $\mathbf{p H = 4}$ & $\mathbf{p H = 6}$ & $\mathbf{p H = 8}$ & $\mathbf{p H = 1 0}$ \\
\hline$\alpha$ & 2 & 2 & 2 & 2 & 2 \\
$R^{2}$ & 0.922 & 0.403 & 0.851 & 0.979 & 0.934 \\
$K\left(\mathrm{~m}^{3} / \mathrm{kg} . \mathrm{s}\right)$ & $3.333 \times 10^{-3}$ & $1.667 \times 10^{-4}$ & $3.333 \times 10^{-4}$ & $1.667 \times 10^{-3}$ & $1.667 \times 10^{-4}$ \\
$\beta_{B r}\left(\mathrm{~m}^{3} / \mathrm{kg} . \mathrm{s}\right)$ & $6.667 \times 10^{-3}$ & $3.333 \times 10^{-4}$ & $6.667 \times 10^{-3}$ & $3.333 \times 10^{-3}$ & $3.333 \times 10^{-4}$ \\
$K_{R}\left(\mathrm{~m}^{3} / \mathrm{s}\right)$ & $1.130 \times 10^{-16}$ & $1.231 \times 10^{-16}$ & $1.130 \times 10^{-16}$ & $1.242 \times 10^{-16}$ & $1.243 \times 10^{-16}$ \\
$\varepsilon_{p}\left(\mathrm{~kg}^{-1}\right)$ & $5.902 \times 10^{13}$ & $2.708 \times 10^{12}$ & $5.902 \times 10^{13}$ & $2.684 \times 10^{13}$ & $2.683 \times 10^{12}$ \\
$\tau_{1 / 2}(s)$ & 28.122 & 562.366 & 281.193 & 56.237 & 562.237 \\
$(S P)_{0}^{c}\left(\mathrm{~kg} / \mathrm{m}^{3}\right)$ & 0.100 & 1.429 & 1.111 & 0.556 & 1.429 \\
$\left(N_{p}\right)_{0}^{c}\left(\mathrm{~m}^{3}\right)$ & $0.602 \times 10^{26}$ & $8.603 \times 10^{26}$ & $6.891 \times 10^{26}$ & $3.346 \times 10^{26}$ & $8.603 \times 10^{26}$ \\
$-r\left(\mathrm{~kg} / \mathrm{m}^{3} . s\right)$ & $3.333 \times 10^{-3} \mathrm{c}^{2}$ & $1.667 \times 10^{-4} \mathrm{c}^{2}$ & $3.333 \times 10^{-4} \mathrm{c}^{2}$ & $1.667 \times 10^{-3} \mathrm{c}^{2}$ & $1.667 \times 10^{-4} \mathrm{c}^{2}$ \\
\hline
\end{tabular}

Table 5: Coag-flocculation Functional parameters for varying $\mathrm{pH}$ and constant dosage of $0.5 \mathrm{~kg} / \mathrm{m}^{3} \mathrm{ABC}$

\begin{tabular}{llllll}
\hline Parameter & $\mathbf{p H = 2}$ & $\mathbf{p H = 4}$ & $\mathbf{p H = 6}$ & $\mathbf{p H = 8}$ & $\mathbf{p H = 1 0}$ \\
\hline$\alpha$ & 2 & 2 & 2 & 2 & 2 \\
$R^{2}$ & 0.921 & 0.549 & 0.986 & 0.979 & 0.934 \\
$K\left(\mathrm{~m}^{3} / \mathrm{kg} . \mathrm{s}\right)$ & $3.333 \times 10^{-3}$ & $3.333 \times 10^{-4}$ & $5.000 \times 10^{-4}$ & $1.667 \times 10^{-3}$ & $1.667 \times 10^{-4}$ \\
$\beta_{B r}\left(\mathrm{~m}^{3} / \mathrm{kg} . \mathrm{s}\right)$ & $6.667 \times 10^{-3}$ & $6.667 \times 10^{-4}$ & $10.000 \times 10^{-4}$ & $3.333 \times 10^{-3}$ & $3.333 \times 10^{-4}$ \\
$K_{R}\left(\mathrm{~m}^{3} / \mathrm{s}\right)$ & $1.587 \times 10^{-16}$ & $1.408 \times 10^{-16}$ & $1.587 \times 10^{-16}$ & $1.408 \times 10^{-16}$ & $1.121 \times 10^{-16}$ \\
$\varepsilon_{p}\left(\mathrm{~kg}^{-1}\right)$ & $4.200 \times 10^{13}$ & $4.735 \times 10^{12}$ & $3.151 \times 10^{12}$ & $2.367 \times 10^{13}$ & $2.974 \times 10^{12}$ \\
$\tau_{1 / 2}(s)$ & 28.119 & 281.191 & 187.459 & 56.237 & 562.366 \\
$(S P)_{0}^{c}\left(\mathrm{~kg} / \mathrm{m}^{3}\right)$ & 0.769 & 1.429 & 1.111 & 0.323 & 1.429 \\
$\left(N_{p}\right)_{0}^{c}\left(\mathrm{~m}^{-3}\right)$ & $0.602 \times 10^{26}$ & $8.603 \times 10^{26}$ & $6.891 \times 10^{26}$ & $3.346 \times 10^{26}$ & $8.603 \times 10^{26}$ \\
$-r\left(\mathrm{~kg} / \mathrm{m}^{3} . s\right)$ & $3.333 \times 10^{-3} \mathrm{c}^{2}$ & $3.333 \times 10^{-4} \mathrm{c}^{2}$ & $5.000 \times 10^{-4} \mathrm{c}^{2}$ & $1.667 \times 10^{-3} \mathrm{c}^{2}$ & $1.667 \times 10^{-4} \mathrm{c}^{2}$ \\
\hline
\end{tabular}


Table 6: Representative values of $K$ (Experimental) and $K_{s}$ (Simulated) at varying dosage and pH

\begin{tabular}{llllll}
\hline $\mathbf{p H}$ & Dosage $\left(\mathbf{k g} / \mathbf{m}^{3}\right)$ & $\mathbf{N}_{\mathbf{0}}\left(\right.$ Particles $\left./ \mathbf{m}^{3}\right)$ & $\mathbf{d}_{\mathbf{0}}(\boldsymbol{\mu m})$ & $\mathbf{K}\left(\mathbf{m}^{3} / \mathbf{k g . s}\right)$ & $\mathbf{K}_{\mathbf{S}}\left(\mathbf{m}^{3} / \mathbf{k g . s}\right)$ \\
\hline 2 & 0.1 & $2.509 \times 10^{26}$ & 1.0 & $1.667 \times 10^{-3}$ & $1.594 \times 10^{-3}$ \\
4 & 0.1 & $7.528 \times 10^{26}$ & 1.0 & $3.333 \times 10^{-4}$ & $3.321 \times 10^{-4}$ \\
6 & 0.1 & $3.169 \times 10^{26}$ & 1.0 & $1 \times 10^{-3}$ & $9.466 \times 10^{-4}$ \\
8 & 0.1 & $6.022 \times 10^{26}$ & 1.0 & $3.333 \times 10^{-4}$ & $3.321 \times 10^{-4}$ \\
10 & 0.1 & $1.004 \times 10^{27}$ & 1.0 & $1.667 \times 10^{-4}$ & $1.494 \times 10^{-4}$ \\
2 & 0.1 & $2.509 \times 10^{26}$ & 1.0 & $1.667 \times 10^{-3}$ & $1.594 \times 10^{-3}$ \\
2 & 0.2 & $3.169 \times 10^{26}$ & 1.0 & $3.333 \times 10^{-3}$ & $3.155 \times 10^{-3}$ \\
2 & 0.3 & $8.603 \times 10^{26}$ & 1.0 & $3.333 \times 10^{-3}$ & $3.487 \times 10^{-3}$ \\
2 & 0.4 & $0.602 \times 10^{26}$ & 1.0 & $3.333 \times 10^{-3}$ & $3.321 \times 10^{-3}$ \\
2 & 0.5 & $4.631 \times 10^{26}$ & 1.0 & $3.333 \times 10^{-3}$ & $3.240 \times 10^{-3}$ \\
\hline
\end{tabular}

Meanwhile, the values of $K$ (now $K_{S}$ ) from equation 38 determined from the simulated light scattering model are in strong agreement with $K$ (from equation 23) determined from experimental jar test. These results underscore the concept of Brownian (rapid) coagflocculation at early time even in situation where independent procedures were employed in the determination of the parameters. The representative's plots for the determination of $K$ and $K_{S}($ simulated $K)$ are presented in Figs 1 to 4.

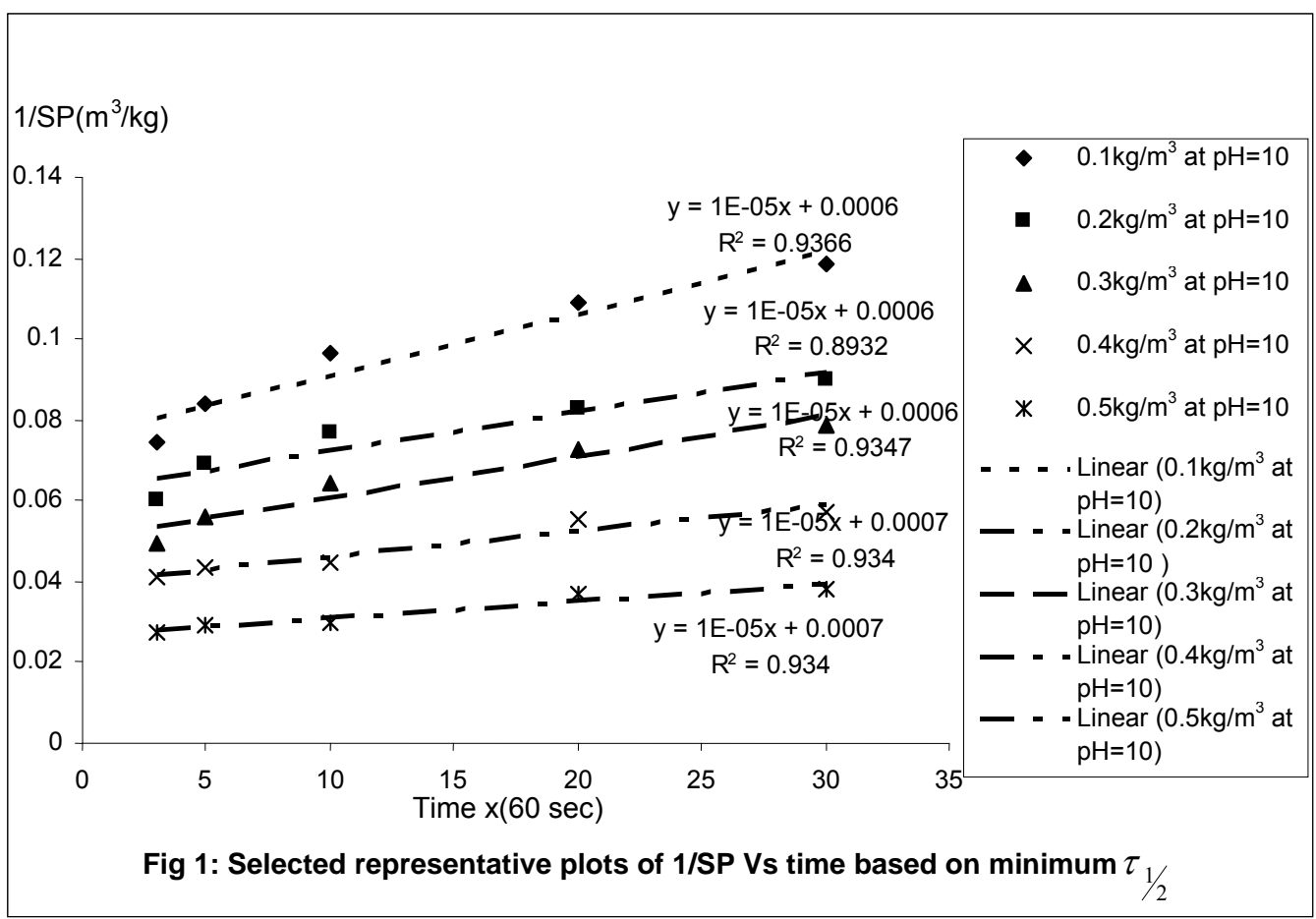




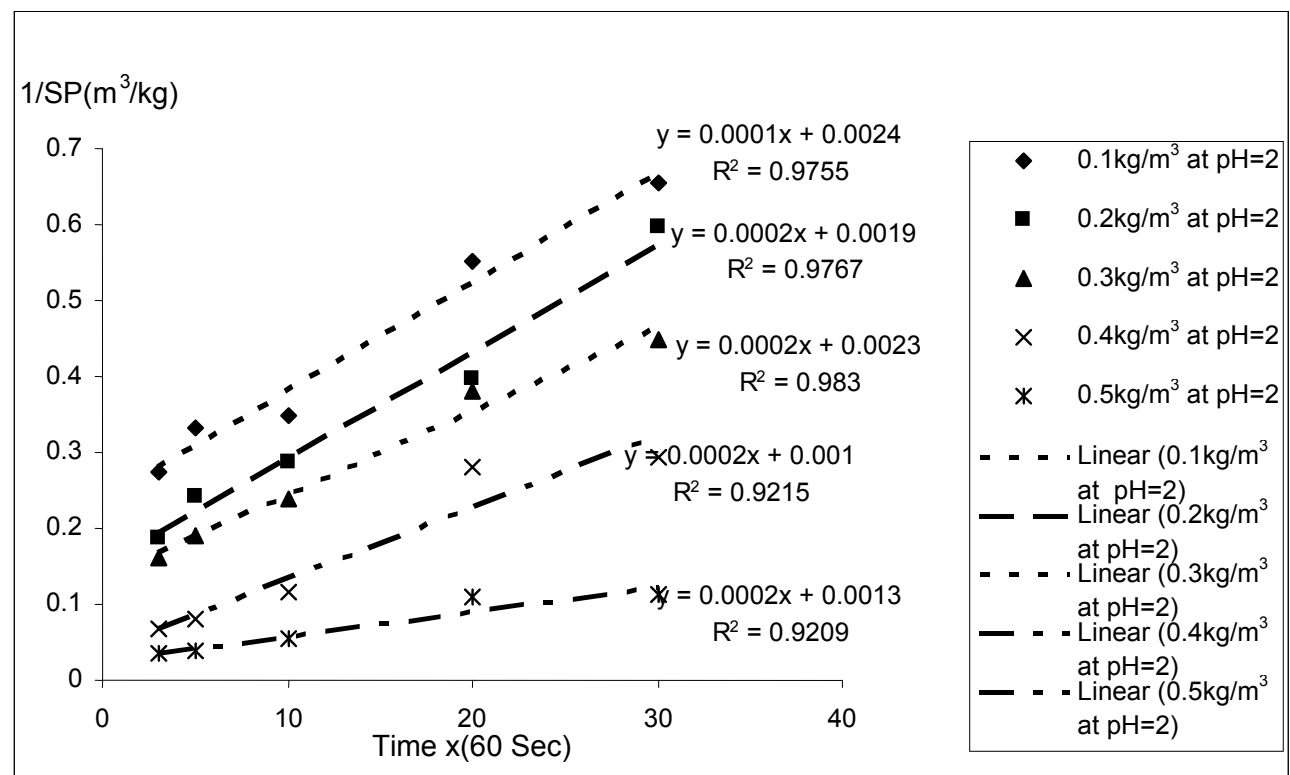

Fig 2: Selected representative plots of 1/SP Vs Time based on maximum $\tau_{1 / 2}$
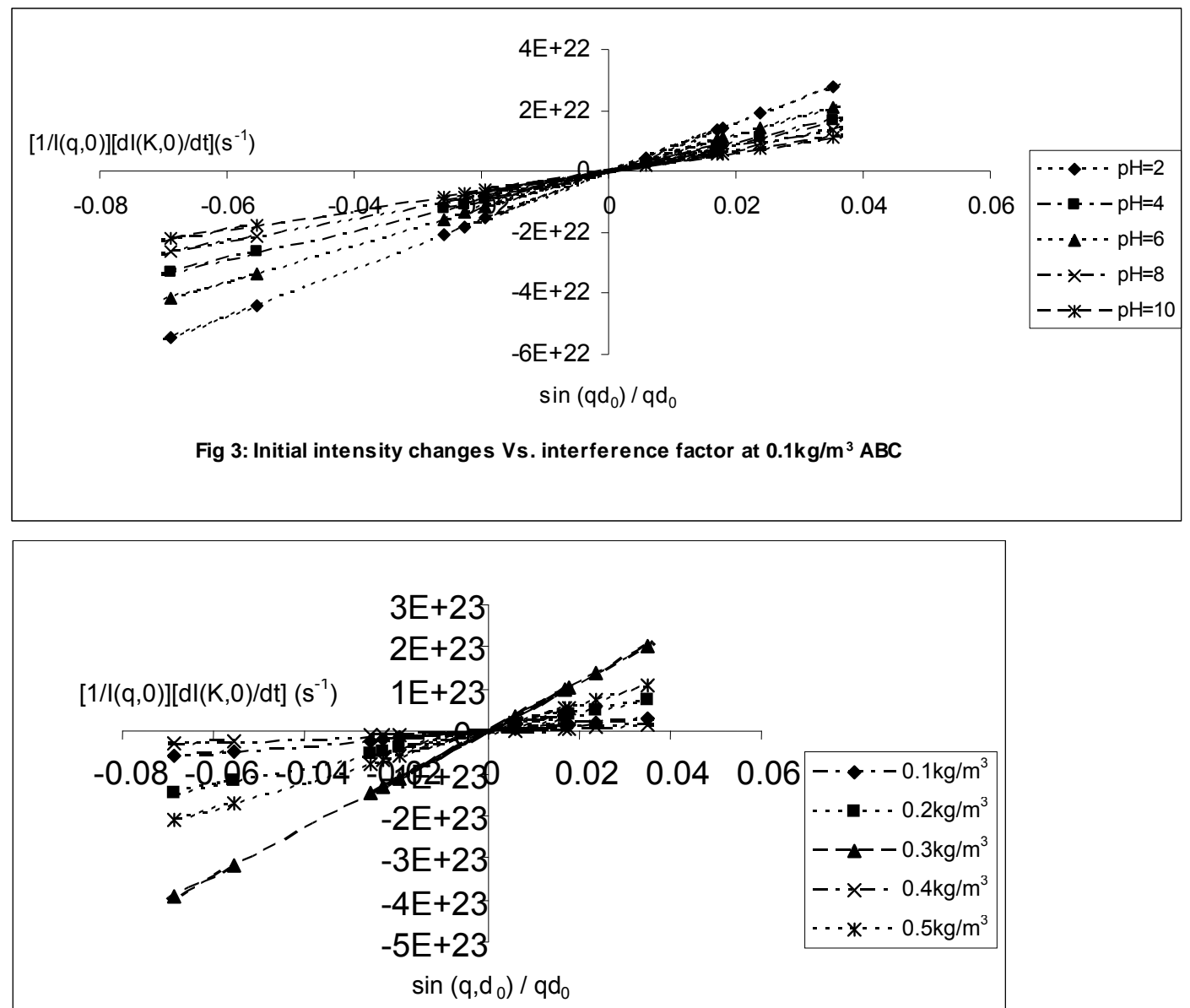

Fig 4: Initial intensity change Vs. interference factor for $A B C$ at $\mathrm{pH}$ of 2 
The discrepancies in $K, K_{R}$ and $(S P)_{0}^{c}$ are explained by the unattainable assumption that mixing of particles and $\mathrm{ABC}$ throughout the dispersion is $100 \%$ efficient before any aggregation occurs. The effect of this limitation will be local increase in particle ratios during the mixing phase given uneven distribution of particles / ABC complexes [18]. Another account is the interplay between the Vander Waal forces and the hydrodynamic interactions which typically alters the theoretically predicted parameter values by a factor of \pm 2 .However, other additional short range forces may represent the most likely explanation for any other remaining discrepancies $[19,20]$.

\subsection{SP $\left(\mathrm{kg} / \mathrm{m}^{3}\right)$ Vs Time plots}

The SP Vs Time plots are presented in Figs 5 to 9. The common trend is that SP reduces with time. This is because as single particles flocculate into large aggregates and settle, the turbidity of the dispersion decreases and the transmission intensity increases. This behavior reflects the complex dependence of turbidity (hence coag-flocculation) on particle number (dropping) and particle size (increasing) over time [18]. The rapid settling of the flocculated particle is shown in Figs 5 to 9 where $90 \%$ of the initial SP concentration of $21204.72 \mathrm{mg} / 1$ were removed at the $3^{\text {rd }}$ minute. This is supported strongly by the values of $\tau_{1 / 2}$ recorded in Tables 1 to 5 where the highest and least coag-flocculation were achieved at $\mathrm{pH}$ of 2 and 10 respectively.

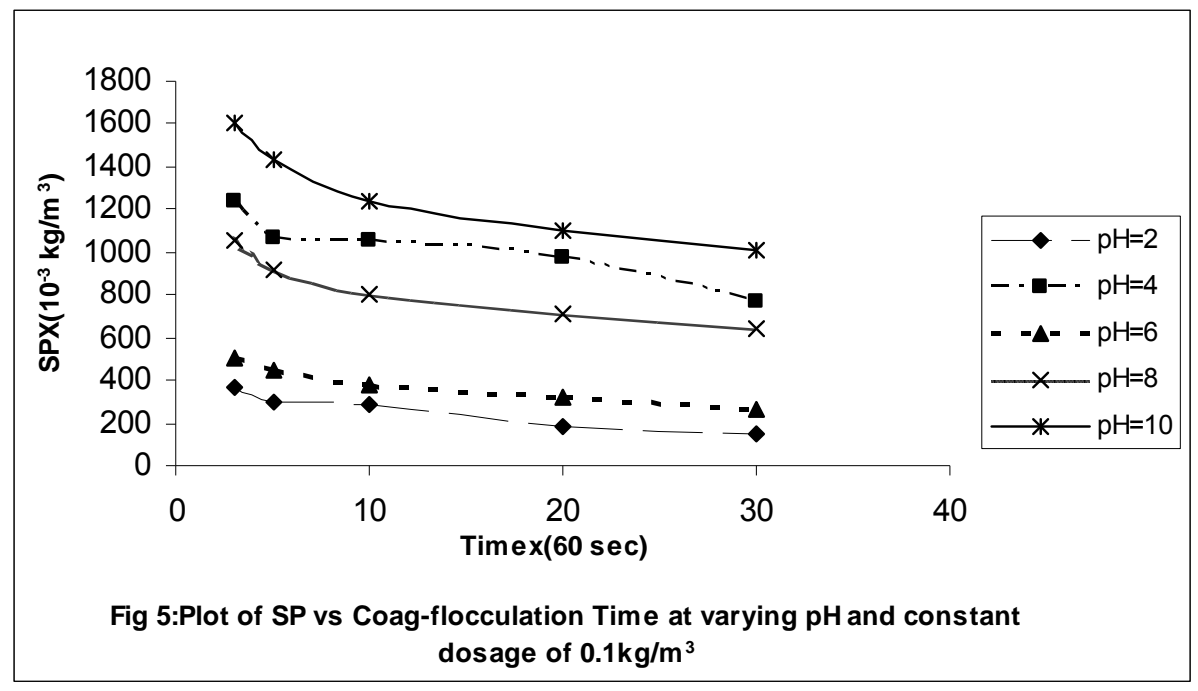



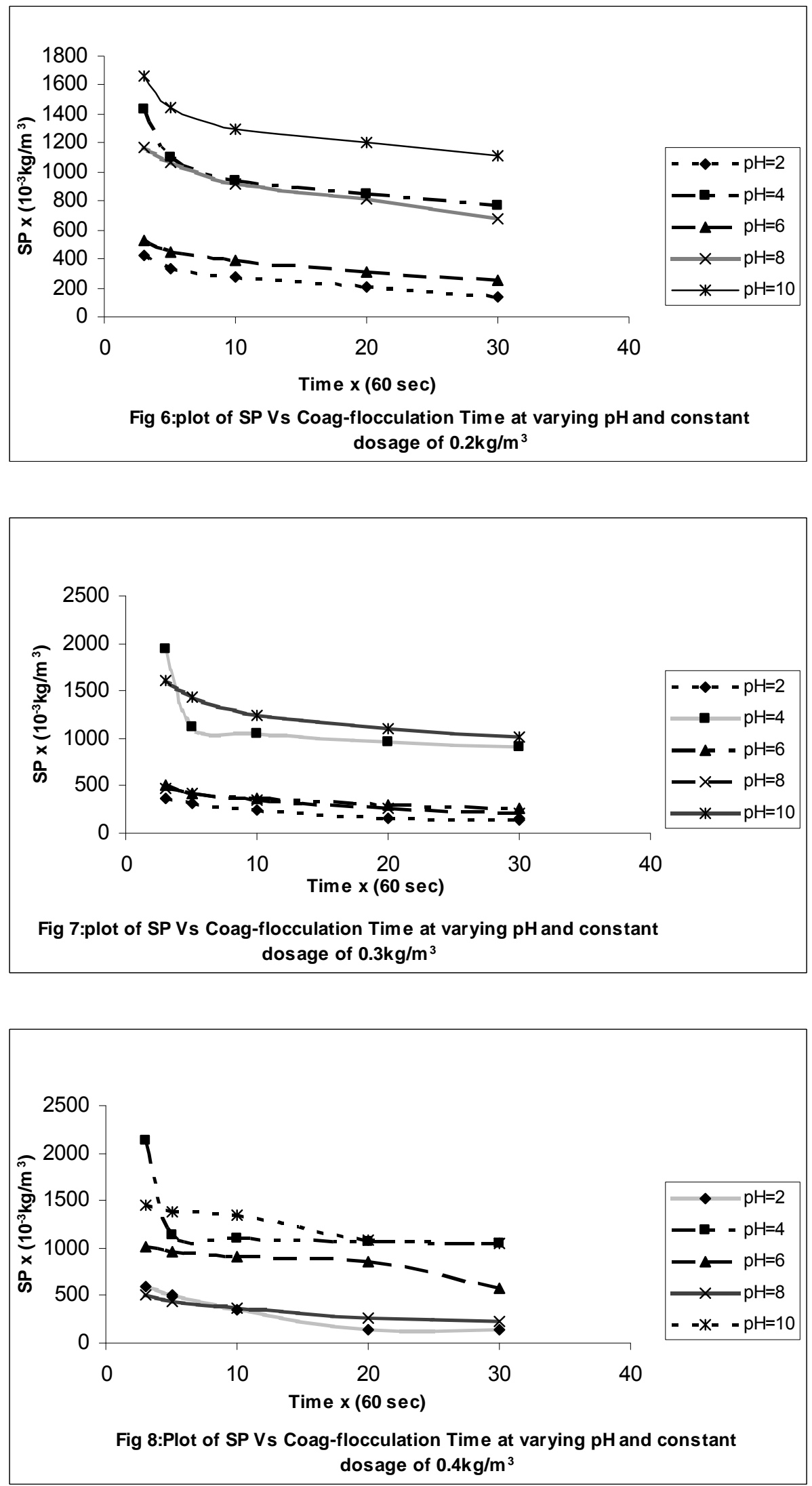


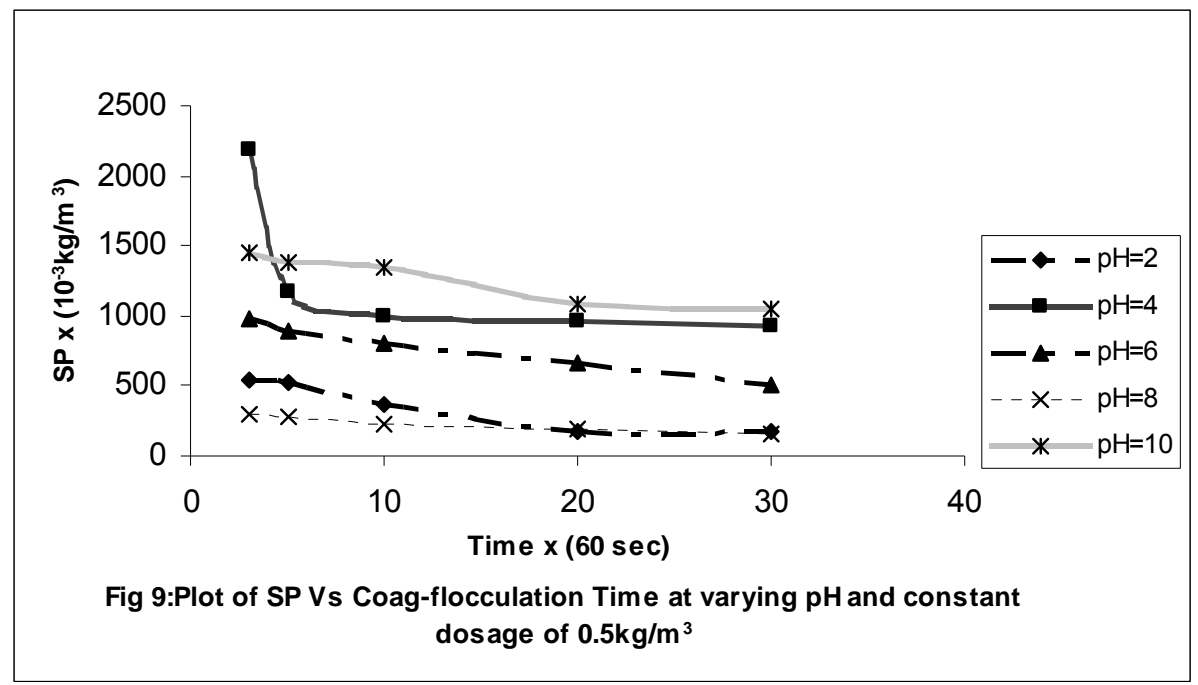

\subsection{Efficiency E (\%) vs. time}

Plots of E (\%) Vs time are presented in Figs 10 to 14 . The E (\%) indicates the effectiveness of $\mathrm{ABC}$ to remove suspended particle (turbidity) form the effluent. The plots show that the least $\mathrm{E}>89.00$ justifies the effectiveness of $\mathrm{ABC}$. This collaborates with the values of $\tau_{1 / 2}$ and real life application of coag-flocculation in which $90 \%$ of the particle removal is usually achieved within the first five minutes of the process. Observation shows that the best coagflocculation was achieved at $\mathrm{pH}$ of 2 followed by 6 and 8 .

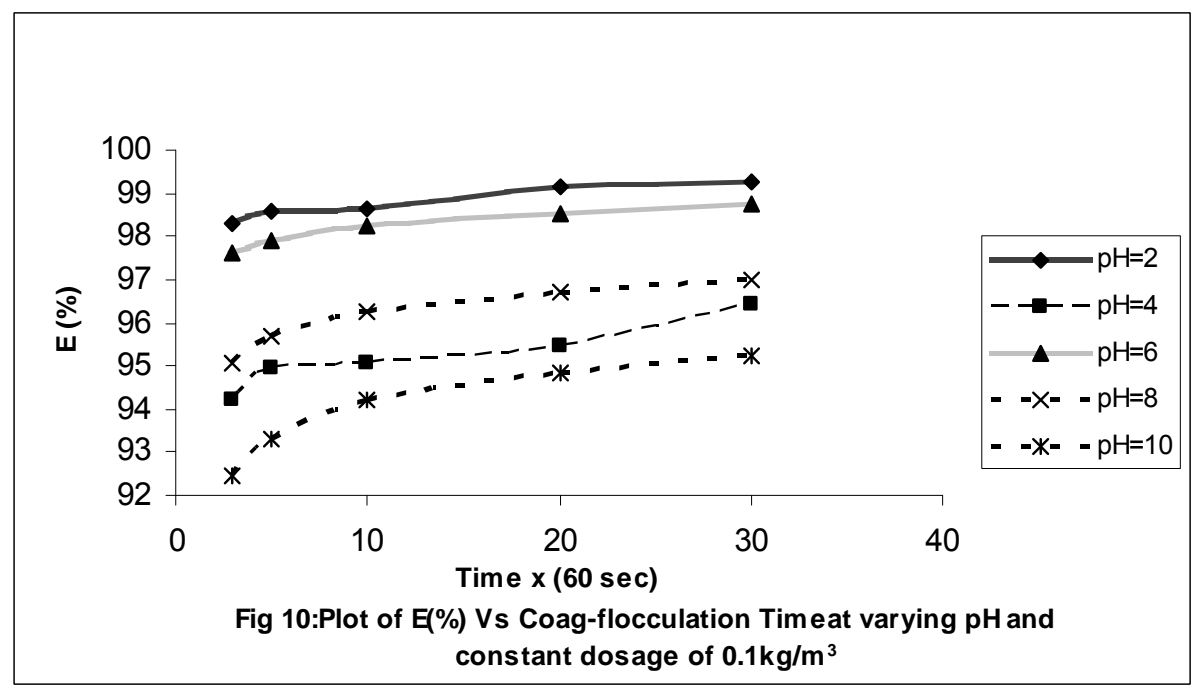



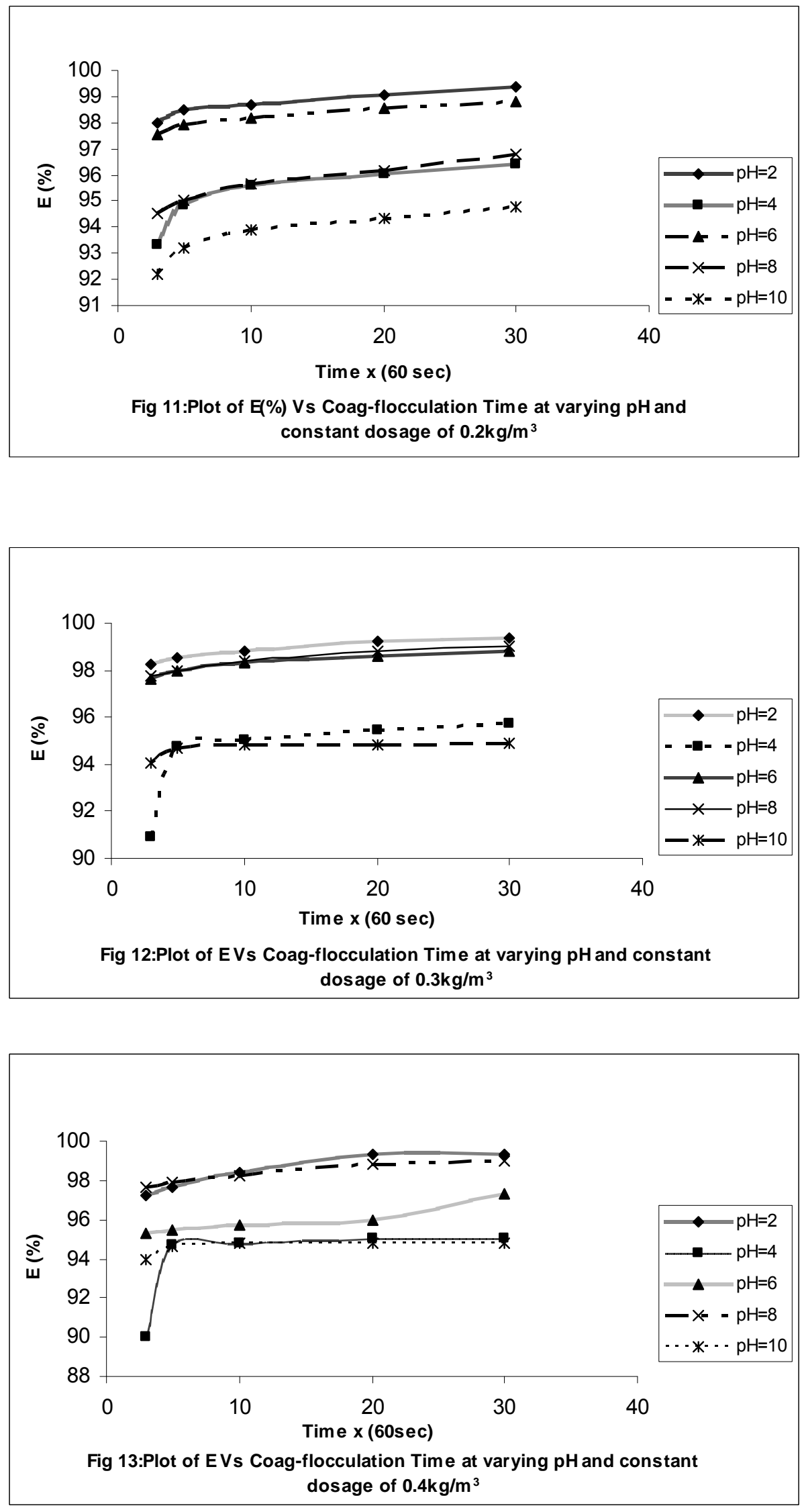


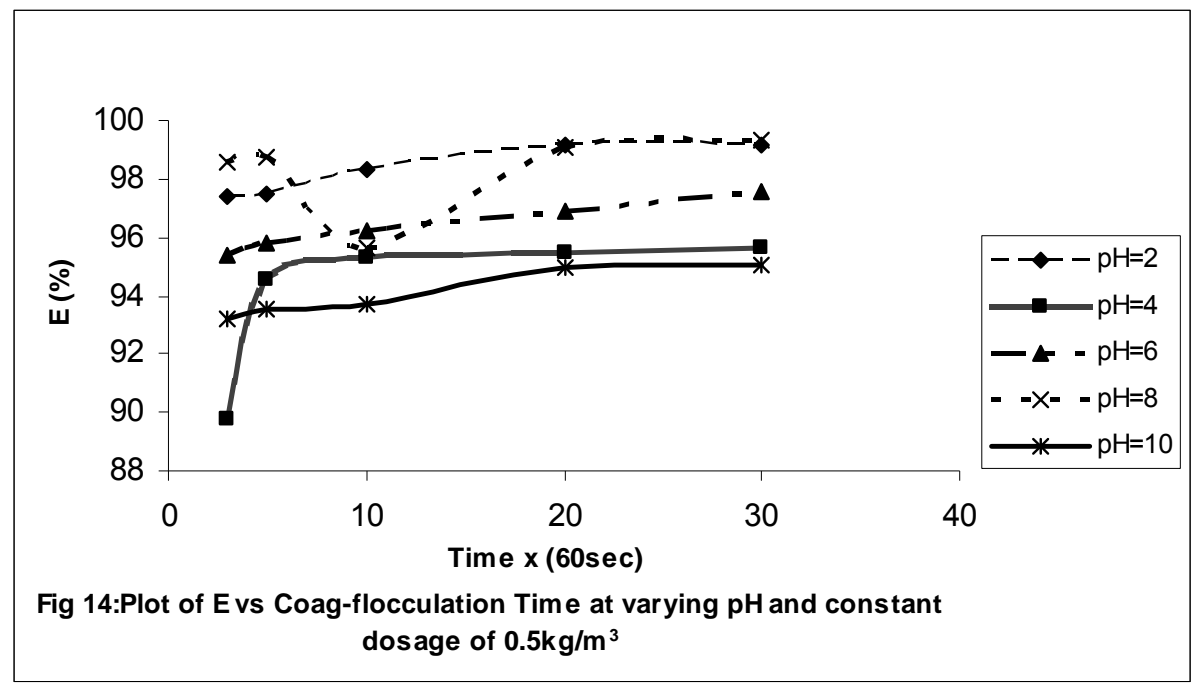

\subsection{E (\%) vs. pH}

This is presented in Fig 15. It indicates the performance of various doses of $A B C$ at varying $\mathrm{pH}$. Interestingly, all the doses have a similar trend having their maxima at $\mathrm{pH}=2$ and minima at $\mathrm{pH}=10$.All doses have the same $\mathrm{E}$ at $\mathrm{pH}$ of 2,indicating that dose does not affect the $\mathrm{E}(\%)$ at $\mathrm{pH}$ of 2 .

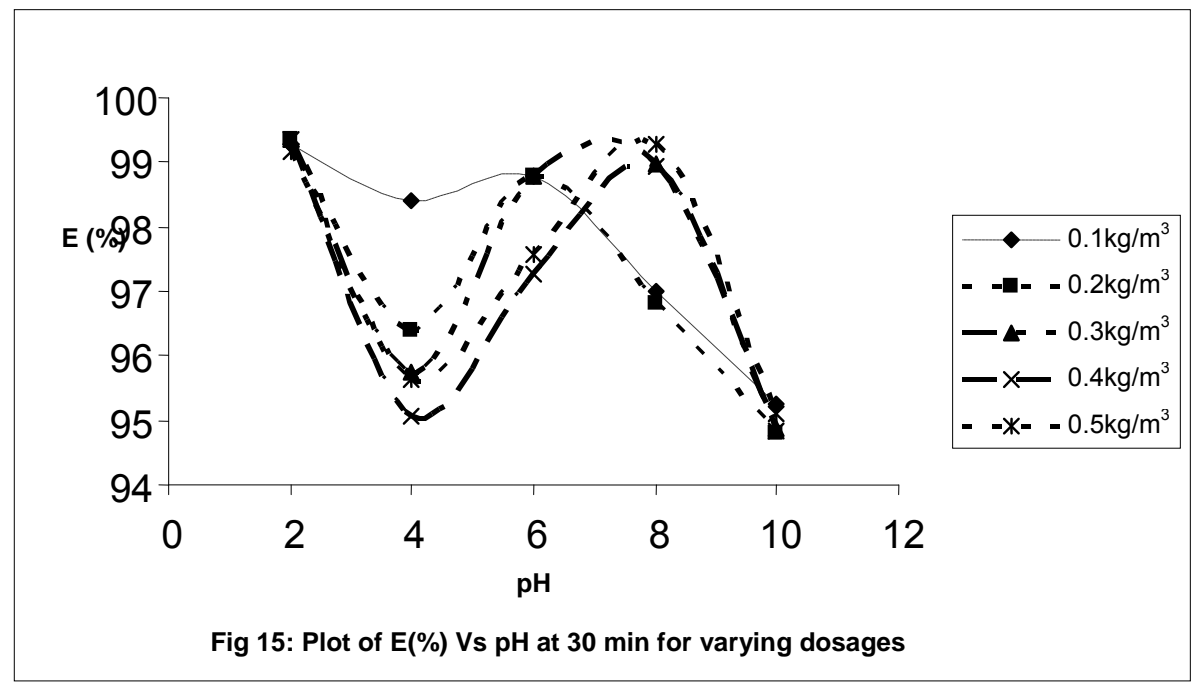

\subsection{E (\%) vs. Dosage $\left(\mathrm{kg} / \mathrm{m}^{3}\right)$}

This is presented in Fig 16. The optimum dosages are $0.1 \mathrm{~kg} / \mathrm{m}^{3}$ and $0.3 \mathrm{~kg} / \mathrm{m}^{3}$ at $\mathrm{E}=$ $99.3722 \%$ and $\mathrm{pH}=2$.It confirms the observation made in fig $15 . \mathrm{pH}$ of 10 has the least $\mathrm{E}(\%)$ for all the dosages. 


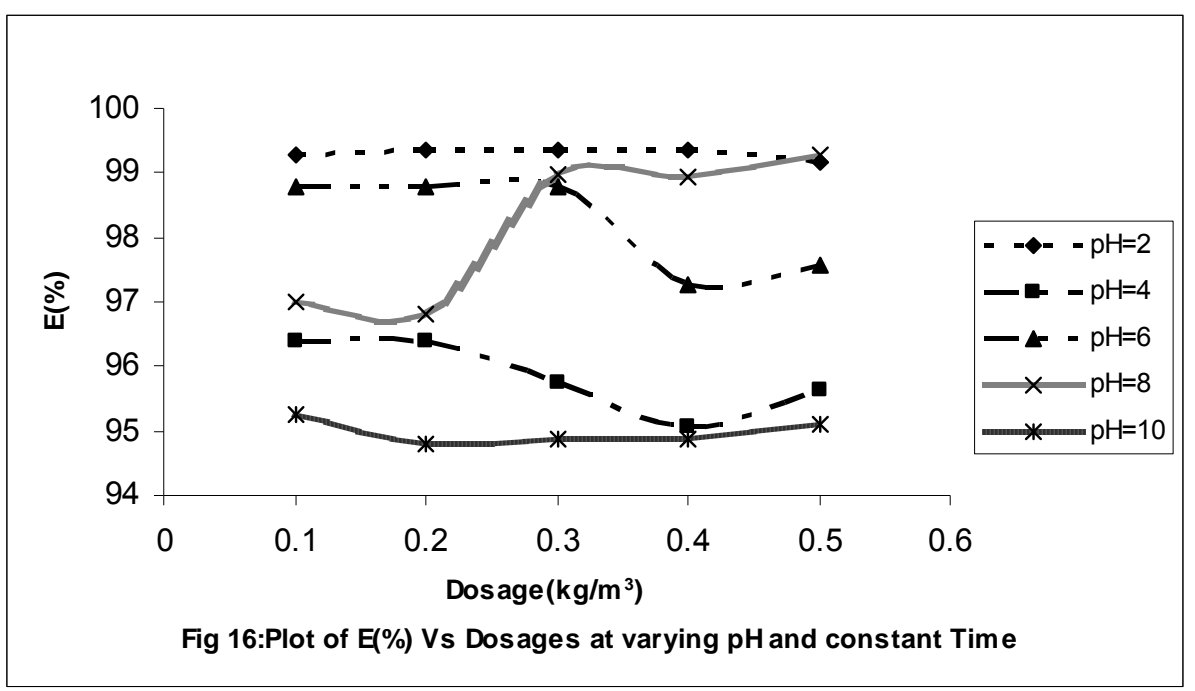

\subsection{Time Evolution of the Cluster Size Distribution}

The representative plots (here $\mathrm{N}_{\mathrm{i}}$ given in particles $/ \mathrm{m}^{3}$ ) are presented in Figs 17 and 18 . The discussion is presented in two cases as follows:

Case I: Consider Fig 17. The particle distributions expected in a typical coag-flocculation process is shown here. The curves $\mathrm{N}_{\mathrm{i}}$ Vs. $t$, beginning with twins (doublets) passes through a maxima because they are absent at the initial instant $\left(\mathrm{t}=0, \mathrm{~N}_{2}=0\right)$ and at the end of coagflocculation process $\left(\mathrm{t}=\infty, \mathrm{N}_{2}=0\right)$. The number of primary particles (singlets) can be seen to decrease more rapidly than the total number of particles. For all consolidated particles, the curves pass through maxima whose height lowers with an increase consolidation.

The curves are expected in coag-flocculation where there is absence of excessive colloidal entrapment and high shear resistance. Mainly, the dominant mechanism in these graphs are charge neutralization combined with low bridging to ensure moderate speed of coagflocculation. The discrete nature of formation of $\mathrm{N}_{1}, \mathrm{~N}_{2}$, and $\mathrm{N}_{3}$ is associated with moderate energy barrier.

Case II: Consider Fig 18.This is the case in which the values of $\mathrm{N}_{3}$ and $\sum \mathrm{N}_{\mathrm{i}}$ are close such that their variation with time is near same. Also, similar trend with respect to $\mathrm{N}_{2}$ and $\mathrm{N}_{\mathrm{i}}$ is obtained. The plot indicates that there exists a wide margin of difference in concentration values between the pair of $\left(\mathrm{N}_{3}\right.$ and $\left.\sum \mathrm{N}_{\mathrm{i}}\right)$ and $\left(\mathrm{N}_{2}\right.$ and $\left.\mathrm{N}_{\mathrm{i}}\right)$. The implication is the existence of high shear force and resistance to collision. This is clearly demonstrated by the value of $\tau_{1 / 2}$ which is the highest recorded. This is an indication of high zeta potential associated with the process. 

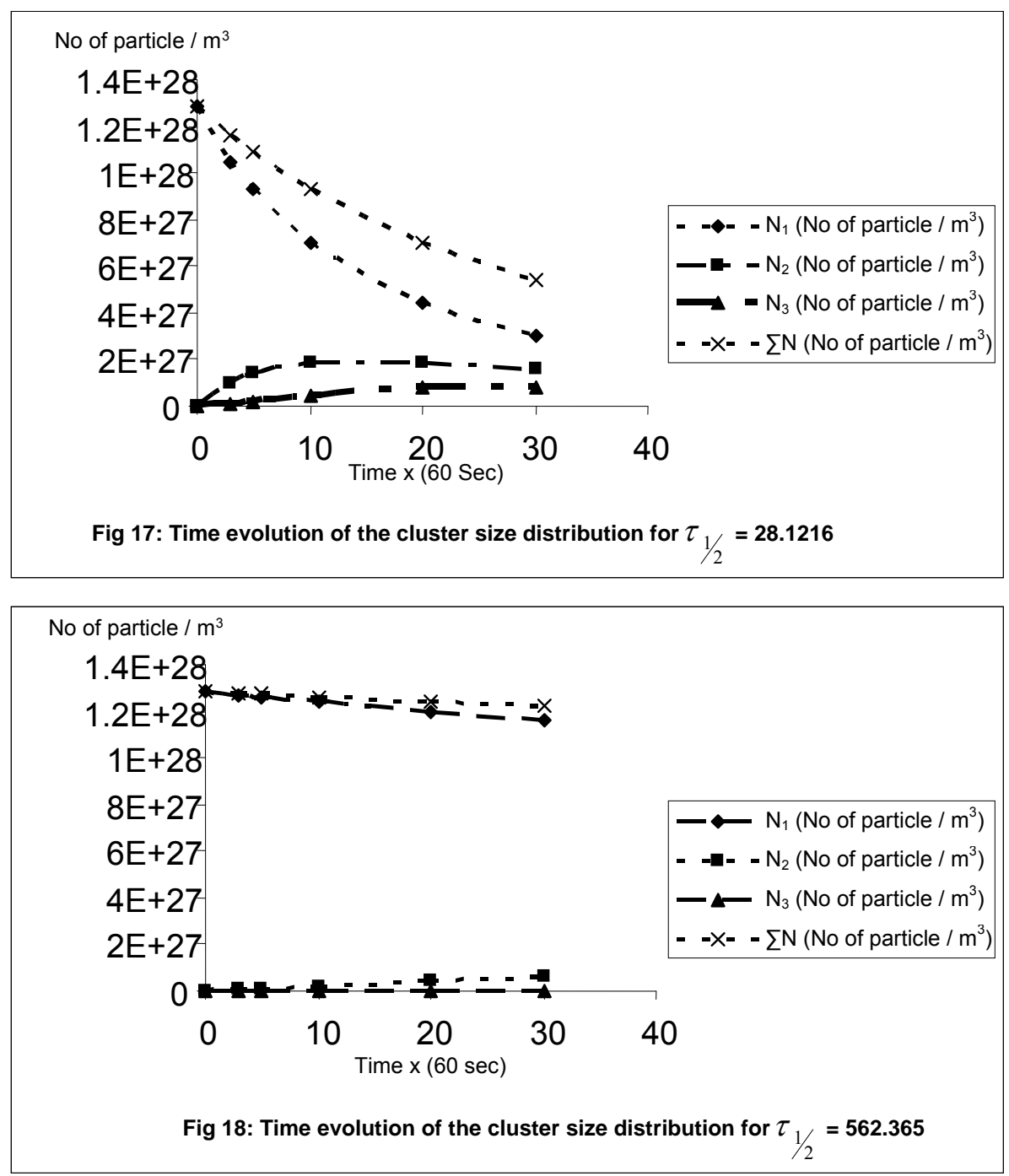

\section{CONCLUSION}

The efficiency of $\mathrm{ABC}$ recorded presents it as a potential source of organic derived coagulant that can be applied in large scale water treatment .The optimum dosages , $\mathrm{pH}$ and $\tau_{1 / 2}$ for the coag-flocculation are $\left(0.3 \mathrm{~kg} / \mathrm{m}^{3}\right.$ and $\left.0.2 \mathrm{~kg} / \mathrm{m}^{3}\right), 2$ and 28 seconds respectively. The obtained results are generally in agreement with previous works $[5,11,20,21]$ and in conformity with perikinetic theory.

\section{NOMENCLATURE}

$K$ :Menkonu coag-flocculation reaction rate constant

$\beta_{B R}$ : Collision factor for Brownian Transport

$\varepsilon_{p}$ : Collision Efficiency

$\tau_{1 / 2}$ : Coagulation Period / Half life

$E$ : Coag-flocculation Efficiency 
$R^{2}$ : Coefficient of Determination

$\alpha$ : Coag-flocculation reaction order

$-r$ : Coag-flocculation reaction rate

$(S P)_{0}^{c}$ : Computed initial suspended particle $\left(\mathrm{kg} / \mathrm{m}^{3}\right)$

$J_{f}:$ Flux

$f_{d}$ : Drag force

$K_{S}: K$ value obtained from simulation.

ABC: Afzelia bella coagulant

$d_{o}$ : Hard core interaction diameter of the primary particle.

$a$ : Radius of the primary particle

\section{REFERENCES}

[1] Ma, J.J., Li, G., Chen, G.R., Xu, G.O., and Cai, G.Q., 2001, "Enhanced coagulation of surface waters with high organic content by permanganate perooxidation" Water science and Technology: Water Supply, Vol 1,pp. 51-61

[2] Diterlizzi, S.D., 1994, Introduction to Coagulation and Flocculation of Waste water, Environmental System Project, U.S.A ,pp 1-4.

[3] Edzwald, J.K.,1987, “Coagulation - sedimentation filtration process for removing organic substances in drinking and waste water.”,Noyes Data Corporation ,Park Bridge ,New Jersey, pp 26-27.

[4] O'Meila C.R., 1978, Coagulation in waste water treatment : The scientific basis of flocculation (NATO Advanced study Inst. Series E, Appl.Sc.No 27), In : Sijtholf and Noordhoff,Alpenan den Rijn, pp 219-268, (Ives ,K.J., Ed.),Netherlands.

[5] Jin, Y., 2005, Use of high Resolution Photographic Technique for studying Coagulation/flocculation in water treatment, M.Sc thesis, University of Saskatchewan, Saskatoon, Canada.

[6] Ezeagu I E, Metges C.C, Proll .J, Petzke K.J, and Akinsoyinu A.O, 2006, Chemical composition and nutritive value of some wild gathered tropical plant seeds; Deutscher Akademischer Austaischdienst, German Institute for Human Nutrition Bonn Germany.pp34

[7] Hunter, R.J., 1993; Introduction to Modern Colloid Science, Oxford University Press, New York,pp 33-38;289-290

[8] Thomas, D.N., Judd, S.J., and Fawcett, N., 1999; " Flocculation modeling: A review". Water Resources, Vol 33, pp. 1579-1592.

[9] Swift, D.L., and Friedlander, S.K., 1964, "The coagulation of hydrolysis by Brownian motion and laminar shear flow." Journal of Colloid Science, Vol 19, Pp 621.

[10] Von Smoluchowski, M., 1917; "Versucheiner Mathematischen Theorie der Koagulations Kinetic Kolloider Lousungen.” Z. Phys. Chem. 92: Pp 129-168.

[11] Van Zanten, J.H., and Elimelech M., 1992; "Determination of Rate constants by multi angle light scattering." Journal of colloid and interface Vol 154, pp 621

[12] Fridkhsberg, D.A., 1984; A course in Colloid Chemistry; Mir Publishers Moscow, Russia. pp 266-268 
[13] Adebowale, Y.A., and Adebowale, K.A., 2007; "Evaluation of the Gelation characteristics of Mucuna Bean Flour and Protein isolate." Electronic Journal of Environmental, Agricultural and Food Chemistry, Vol 6,2007,pp 2243-2262.

[14] Water Specialist Technology (WST) 2003; About Coagulation and Flocculation: Information Bulletins, U.S.A. pp:1-10

[15] AWWA 2005; American Water Works Association;Standard Methods for the Examination of Water and Waste water Effluent, New York, U.S.A.

[16] Ravina .L, 1993; Everything you need to know about coagulation and flocculation, $4^{\text {th }}$ Ed .Zeta Meter .Inc.Virginia USA.

[17] Nelkon M.; 1981;Principles of physics $4^{\text {th }}$ Edn .Collins International Textbook DepartmentLondon.

[18] Yates, P., Yan, Y., Jamson, G. J., and Biggs, S., 2001; "Heteroaggregation of particle system: Aggregation Mechanisms and aggregate structure determination." $6^{\text {th }}$ World Congress of Chemical Engineering,Melbourne,Australia,23-27 September,2001. pp: 1-10

[19] Holthof, H., Schmitt, A., Ferńandez-Barbero,M., Borkovec, M., Cabrerizo-Vilehez, P., Schurtenberger, P., and Hidalgo-Alvarez, R., 1997 ;"Measurement of Absolute Coagulation Rate Constants for Colloidal Particles: Comparison of Single and Multiparticle Light Scattering Techniques.”Journal of Colloid and Interface Science, Vol 192, Pp 463-470.

[20] Holthof, H., Egelhaaf, S.U., Borkovec, M., Schurtenberger, P., and Sticher, H., 1996; "Coagulation Rate Measurement of Colloidal Particles by Simultaneous Static and Dynamic Light Scattering.”Langmuir Vol 12, Pp 5541.

[21] Menkiti M.C., Nnaji P.C., Nwoye C.I., Onukwuli O.D, 2010; Coag-flocculation kinetics and functional parameters response of Mucuna seed coagulant to $\mathrm{pH}$ variation in organic rich coal effluent medium. Journal of minerals and material characterization and Engineering, Vol 9, no 2,Pp 89-103. 